\title{
POLICY RULES, REGIME SWITCHES, AND TREND INFLATION: AN EMPIRICAL INVESTIGATION FOR THE UNITED STATES
}

\author{
Efrem Castelnuovo \\ University of Padua \\ and \\ Bank of Finland \\ LuCiano Greco \\ University of Padua \\ DAVIDE RAGGI \\ University of Bologna \\ and \\ Johns Hopkins University (SAIS Centre)
}

This paper estimates Taylor rules featuring instabilities in policy parameters and switches in policy shocks' volatility for the post-World War II (WWII) U.S. economy. We contrast a rule embedding a fixed-inflation target with another featuring trend inflation, i.e., a time-varying inflation target. The rule embedding trend inflation turns out to be (a) empirically superior according to a marginal likelihood-based comparison and (b) more able to pin down some relevant episodes of the post-WWII U.S. monetary policy history. Estimates conducted with Greenbook data confirm the empirical superiority of the rule featuring a time-varying inflation target. A comparison with recently published estimates of trend inflation is also conducted.

Keywords: Policy Switches, Heteroskedasticity, Trend Inflation, Inflation Gap Persistence, Markov-Switching Models

\footnotetext{
We are grateful to the Editor, William A. Barnett, an anonymous associate editor, and two anonymous referees for their comments and suggestions, which greatly improved the quality of the paper. We also thank Gianni Amisano, Francesco Bianchi, Giacomo Carboni, Matteo Ciccarelli, Patrick Crowley, Troy Davig, Esa Jokivuolle, David Mayes, Jouko Vilmunen, and Paolo Zagaglia, as well as participants at presentations held at the University of Padua, Computational Economics and Finance (Paris), the Bank of Finland, the Italian Congress of Econometrics and Empirical Economics (Ancona), the Society for Nonlinear Dynamics and Econometrics (Atlanta), and the Royal Economic Society (Guildford) for useful feedbacks. We thank Olivier Coibion, Peter Ireland, and Sharon Kozicki for graciously sharing their replication codes and data with us. The opinions expressed in this paper do not necessarily reflect those of the Bank of Finland. All remaining errors are ours. Address correspondence to: Efrem Castelnuovo, University of Padua and Bank of Finland, via del Santo 33, I-35123; e-mailt: efrem.castelnuovo@unipd.it.
} 


\section{INTRODUCTION}

Since the seminal contribution by Taylor (1993), simple policy rules-also known as "Taylor rules"- have been largely employed to describe the monetary policy conduct of a variety of economies, including the United States [Clarida et al. (2000)], the G7 countries [Clarida et al. (1998)], the Euro Area [Gerlach and Schnabel (2000), Castelnuovo (2007)], and some transition economies [Golinelli and Rovelli (2003)].

Most of these contributions assume (i) constant monetary policy reactions to inflation and output (in deviations with respect to their targets), (ii) homoskedastic monetary policy shocks, and (iii) fixed targets. For the U.S. economy, however, these assumptions are problematic. Clarida et al. (2000) and Lubik and Schorfheide (2004) document breaks in the Federal Reserve's reaction to inflation. Castelnuovo and Surico (2010) and Castelnuovo (2012b) exploit a policy break to interpret the instability in the estimated response of inflation to a monetary policy shock found in standard VARs and in small-scale structural models. A different impact on inflation expectations in the pre- vs. post-Volcker regimes is found by Castelnuovo (2010). As for monetary policy shocks' volatility, Schorfheide (2005), Sims and Zha (2006), Justiniano and Primiceri (2008), and Liu et al. (2011) support the relevance of heteroskedasticity to explaining U.S. macroeconomic dynamics.

This paper describes the post-World War II (WWII) Federal Reserve's monetary policy conduct with an extremely flexible Taylor rule in which policy parameters are free to switch between states, policy shocks are heteroskedastic, and the inflation target is allowed to change over time. To our knowledge, this is the first contribution jointly dealing with a time-varying trend inflation process, shifts in the policy parameters, and heteroskedastic shocks. The ultimate goal is acquiring a better understanding of the features characterizing U.S. monetary policy conduct.

We pay particular attention to the process of the inflation target. Evidence in favor of a time-varying inflation target is provided by Kozicki and Tinsley (2005, 2009), Ireland (2007), Stock and Watson (2007), Cogley and Sbordone (2008), Coibion and Gorodnichenko (2011), and Aruoba and Schorfheide (2011). According to Cogley et al. (2010), trend inflation is the single most important factor behind U.S. inflation dynamics. ${ }^{1}$ Trend inflation, however, is typically omitted in empirical analysis dealing with the identification of policy regime shifts. When one seeks to characterize the post-WWII U.S. policy conduct, this omission may bias the estimated parameters of the Taylor rule, the estimated probabilities of being in certain economic states, and so on. It is therefore of interest to assess the empirical relevance of this omission. We thus contrast two estimated policy rules, one featuring a fixed inflation target and another one featuring trend inflation, to assess to what extent the omission of the time-varying inflation target may affect (i) the statistical fit of the federal funds rate, (ii) the estimated parameters of the simple policy rule, (iii) the estimated probability of being in an "active" monetary policy regime,${ }^{2}$ and (iv) the estimated probability of being in a "high-volatility" regime. 
We find evidence in favor of policy switches and trend inflation as relevant ingredients to describe post-WWII U.S. monetary policy conduct. Crucially, the timing of the switches in the policy conduct is sensitive to the definition of the inflation target policymakers are assumed to consider. In particular, a fixed inflation target leads to underestimation of the length of the regimes during which the Fed has actively fought inflation fluctuations. Moreover, in the presence of a passive regime, the model with trend inflation suggests a reaction to inflation much smaller than that proposed by some previous contributions [see, among others, Clarida et al. (2000) and Lubik and Schorfheide (2004)]. This result suggests that models with a fixed inflation target may underestimate the magnitude of the shift from a passive to an active monetary policy, thus possibly underestimating the relevance of "good policy" as a driver of the U.S. macroeconomic volatilities.

Interestingly, the model with trend inflation appears to capture the changes in the Federal Reserve's chairmanship more accurately than its (restricted) fixed-target counterpart. Regarding the timing issue, shifts in systematic monetary policy conduct are found not to be synchronized with shifts in the volatility of the monetary policy shocks. This result suggests that the popular "pre- vs. postVolcker" split offers just a partial picture of the more complex U.S. monetary policy history. In a section of the paper we show that our trend inflation estimate is quite similar to Ireland's (2007) and Aruoba and Schorfheide's (2011), which are obtained with the employment of methodologies different from ours.

These results are obtained with revised, "latest release" data. As a matter of fact, however, it is more appropriate to use real-time data in estimating policy reaction functions. Following Orphanides (2001), Kozicki and Tinsley (2009), and Coibion and Gorodnichenko (2011), we then perform an investigation with an alternative data set, i.e., the real-time forecasts produced by the staff of the Federal Reserve, also known as "Greenbook forecasts." Our main result, the empirical superiority of a rule featuring trend inflation on top of policy changes and shocks' heteroskedasticity, turns out to be robust to the use of this alternative data set.

Before moving to the next section, we note connections with some closely related studies in the literature. Davig and Doh (2009) and Bianchi (in press) find evidence in favor of recurrent regime switches in the systematic policy conduct and the volatility of policy innovations with Markov-switching DSGE models. However, they assume a fixed inflation target in the entire post-WWII period. Cogley et al. (2010) fit multivariate VARs with drifting coefficients and stochastic volatility to a handful of macroeconomic post-WWII U.S. series and establish that the predictability of the inflation gap evolved over time and fell in the great moderation period. Then they estimate a new Keynesian framework over different, predetermined subsamples and find the enhanced stability of the Fed's inflation target to be the single most important factor behind the reductions in the inflation gap volatility and persistence. Differently from Cogley et al. (2010), we are agnostic as regards the timing of the policy breaks, and let the data free to speak along this dimension. With respect to Davig and Doh (2009) and Bianchi (in press), we deal with a partial equilibrium approach, which is more robust to model 
misspecification. Favero and Monacelli (2005), Sims and Zha (2006) and Davig and Leeper (2006) also perform single-equation estimations and find evidence in favor of regime switches and heteroskedastic monetary policy shocks. ${ }^{3}$ Again, although they assume a stable inflation target, we uncover the role played by trend inflation in these empirical exercises. Schorfheide (2005) finds evidence in favor of a switching inflation target in the context of a small-scale macroeconomic model. Liu et al. (2011) embed Schorfheide's (2005) inflation target process in a medium-scale model featuring heteroskedastic macroeconomic shocks and find support for a constant-trend inflation target over the post-WWII period. In contrast, we focus on an autoregressive process for the inflation target such as the one analyzed by Kozicki and Tinsley (2005), Ireland (2007), Stock and Watson (2007), Cogley and Sbordone (2008), and Cogley et al. (2010), a model that is also consistent with the trend inflation estimates put forward by Coibion and Gorodnichenko (2011) and Aruoba and Schorfheide (2011). ${ }^{4}$ Again, we stress that our contribution is, to the best of our knowledge, the first one to assess the role of a persistent trend inflation process in the class of regime-switching policy rule models.

The structure of the paper is as follows. The next section presents the regimeswitching models we estimate. Section 3 proposes and discusses our empirical findings. Section 4 contrasts our trend inflation estimates with a number of alternatives recently proposed in the literature. Section 5 deals with an alternative data set, the Greenbook forecasts produced by the staff of the Federal Reserve. Section 6 concludes.

\section{MODEL AND ESTIMATION STRATEGY}

\subsection{Empirical Model}

We consider Markov-switching models [Hamilton (1989)] characterized by two latent processes, $\boldsymbol{S}_{1}=\left\{S_{1, t}, t=1, \ldots, T\right\}$ and $\boldsymbol{S}_{2}=\left\{S_{2, t}, t=1, \ldots, T\right\}$, which identify the relevant states regarding policy conduct and conditional variances of the model's shocks, respectively. Our encompassing empirical model reads as follows:

$$
\begin{aligned}
i_{t} & =\left(1-\rho_{S_{1}, t}\right)\left(\bar{r}+\pi_{t}+\alpha_{S_{1}, t} z_{t}+\beta_{S_{1}, t} y_{t}\right)+\rho_{S_{1}, t} i_{t-1}+\epsilon_{S_{2}, t}, \\
\pi_{t}^{*} & =\left(1-\rho_{\pi}\right) \pi^{\mathrm{LR}}+\rho_{\pi} \pi_{t-1}^{*}+\xi_{S_{2}, t}, \\
\pi_{t} & =\pi_{t}^{*}+z_{t}, \\
z_{t} & =\phi_{S_{1, t}} z_{t-1}+\eta_{S_{2}, t}, \\
\epsilon_{S_{2}, t} & \sim \mathcal{N}\left(0, \sigma_{\epsilon S_{2}, t}^{2}\right), \xi_{S_{2}, t} \sim \mathcal{N}\left(0, \sigma_{\xi S_{2}, t}^{2}\right), \eta_{S_{2}, t} \sim \mathcal{N}\left(0, \sigma_{\eta S_{2}, t}^{2}\right),
\end{aligned}
$$

where $i_{t}$ is the short-term nominal interest rate, $\pi_{t}$ is the inflation rate, $y_{t}$ is the output gap, $\bar{r}$ is the unknown long-run real interest rate, $\pi_{t}^{*}$ is the unobservable time-varying inflation target, and $z_{t}=\pi_{t}-\pi_{t}^{*}$ is the inflation gap. In particular, 
$\boldsymbol{S}_{1, t}$ and $\boldsymbol{S}_{2, t}$ are defined as two independent binary Markov chains with transition probabilities from state $i$ to state $j \operatorname{Pr}\left[S_{k, t}=i \mid S_{k, t-1}=j\right]=p_{k, i j}$, where $k \in\{1,2\}$ and $i, j \in\{0,1\}$.

We relax the original Taylor rule along different dimensions. First, we allow (but do not necessarily require) policy parameters to be state-dependent. In particular, in light of the instability of U.S. monetary policy conduct documented by several empirical investigations, we enable the "Taylor parameter" $\alpha$, as well as the remaining policy parameters $\beta$ and $\rho$, to switch between the two states. Second, we assume that the time-varying inflation target follows the autoregressive process (2), whose persistence is captured by the parameter $\rho_{\pi}$ and whose unconditional mean is $\pi^{\mathrm{LR}}$. Following Ireland (2007) and Cogley et al. (2010), we interpret $\pi_{t}^{*}$ as a time-varying inflation target set quarter by quarter by the Fed. One may think of several reasons leading policymakers to adjust their inflation target. An intriguing interpretation is that the Federal Reserve adjusts its target as it acquires more information on the structure of the economy. Changing beliefs about the output inflation may have generated a persistent low-frequency hump-shaped pattern in inflation in the post-WWII period [Cogley and Sargent (2005), Primiceri (2006), Sargent et al. (2006), and Carboni and Ellison (2009)]. The autoregressive process (2) is intended to approximate this learning process.

We assume the inflation gap process $z_{t}$ to follow the autoregressive process (4). This enables us to estimate the persistence of the inflation gap, which is the relevant policy objective (as opposed to raw inflation) in the presence of a drifting inflation target. Consistently, we allow the persistence parameter $\phi_{S_{1, t}}$ to be regime-dependent. Finally, we assume shocks to monetary policy, trend inflation, and the inflation gap to be heteroskedastic, mutually uncorrelated independently distributed martingale differences.

\subsection{Estimation Strategy}

We estimate our model with Bayesian techniques by implementing an efficient Markov chain Monte Carlo (MCMC) strategy through the Gibbs sampler. ${ }^{5}$ To deal with identification issues related to "label-switching" [Hamilton et al. (2007)], we impose some constraints on the parameters' space. In particular, the Taylor principle asserts that monetary authorities can stabilize the economy by moving the policy rate more than one to one in response to inflation swings. As in the original rule [Taylor (1993)], equation (1) has a built-in one-to-one reaction due to the Fisher relationship component. ${ }^{6}$ We then impose $\alpha_{S_{1}=0}>0>\alpha_{S_{1}=1}$; i.e., we identify the active monetary policy with $\alpha_{S_{1}=0}$. Following Cogley et al. (2010), we also assume a lower mean of the inflation gap persistence in correspondence to a tighter systematic policy. Consistently, we employ the priors $\phi_{S_{1}=0} \sim \mathcal{N}(0.4,0.1)$ and $\phi_{S_{1}=1} \sim \mathcal{N}(0.6,0.1)$. Notice that the data are left free to speak as regards the relationship between policy conduct and the inflation gap persistence.

In terms of prior densities, we assume a normal density with mean $2 \%$ and unitary standard deviation for the steady-state real interest rate. The mean value 
is close to that of the sample mean of the ex post real interest rate; its standard deviation allows the data to speak freely as to this constant. In line with the empirical literature on simple rules originated by Clarida et al. (2000), we set the prior mean for the $1+\alpha_{S_{1}=0}$ parameter to 1.7 , with a standard deviation of the normal distribution set to 0.1 . Differently, we set the prior mean for $1+\alpha_{S_{1}=1}$ to 0.7 , a value in line with that for passive monetary policy typically found in the literature. The reaction to the output gap $1+\beta_{S}$ is assumed to be normally distributed with mean 0.25 and standard deviation 0.15 to ensure that the data can offer an indication of this parameter. The mean of the normally distributed prior density on the degree of interest rate smoothing parameter is fixed to 0.8 , and its standard deviation to 0.1 . The variances of the monetary policy shock in both regimes are inverse Gamma distributed, with mean 2.5 and standard deviation 0.75. The prior on the steady-state inflation target is a normal distribution whose mean is $2 \%$, a value typically referred to as the reference value for the Federal Reserve's long-run inflation goal. Moving to the inflation target autoregressive process, we calibrate the mean value of its persistence to 0.9 , a value picking up the persistence documented by, among others, Cogley et al. (2010). We assume the priors on the trend inflation shocks to be the same as those on the policy shocks. Finally, the probabilities of changing regime are Beta distributed with mean 5\% and standard deviation of about 0.02 , values implying some persistence of the regimes we aim at identifying. Table 1 collects our prior densities as characterized by their means and variances, with the exception of the Beta priors for the switching probabilities, which are defined by their shape parameters.

Importantly, we do not take any a priori stand on the timing of any of the switches we model. When investigating parameter instabilities with fixed-coefficient models, researchers typically split the U.S. samples at dates corresponding to the beginning of Paul Volcker's FOMC chairmanship or the great moderation. This choice is somewhat "natural" and clearly based on historical events. However, it has some drawbacks. First, it rules out the possibility of regime switches possibly occurred in the 1960s and during the great moderation. Second, it forces policy parameters and volatility shocks to switch contemporaneously. By contrast, with our approach, which allows policy parameters and shocks to shift independently over time, we are well equipped to detect heteroskedasticity in the policy shocks within a given policy regime.

We focus on two different policy rule models. First, we consider a "Fixed Target" (FT) model featuring $\pi_{t}^{*}=\pi^{\mathrm{LR}}$ at all times. We then contrast it with a more flexible version of the model, which we label "Trend Inflation" (TI), in which the inflation target is allowed to follow the process (2). We fit these two models to U.S. quarterly data spanning the sample 1955:I-2007:II. ${ }^{7}$ We limit our sample to 2007:II to avoid dealing with the nonconventional monetary policy interventions undertaken by the Federal Reserve to tackle the macroeconomic effects of the recent financial crisis. The complexity of such nonconventional monetary policy interventions, jointly with the zero-lower bound hit by the federal funds rate in December 2008, would be hard to describe with a simple monetary policy rule. 
TABLE 1. Estimated monetary policy rules: Fixed target vs. trend inflation, revised data

\begin{tabular}{|c|c|c|c|}
\hline Parameter & Prior & Fixed target & Trend inflation \\
\hline $\bar{r}$ & $\mathcal{N}(2.0,1.0)$ & $\begin{array}{c}3.07 \\
{[2.19,3.88]}\end{array}$ & $\begin{array}{c}2.95 \\
{[1.99,3.76]}\end{array}$ \\
\hline $1+\alpha_{S_{1}=0}$ & $\mathcal{N}(1.7,0.1) \mathbf{I}_{[1,5]}$ & $\begin{array}{c}1.69 \\
{[1.12,2.30]}\end{array}$ & $\begin{array}{c}1.67 \\
{[1.14,2.28]}\end{array}$ \\
\hline $1+\alpha_{S_{1}=1}$ & $\mathcal{N}(0.7,0.1) \mathbf{I}_{[0,1]}$ & $\begin{array}{c}0.79 \\
{[0.47,0.99]}\end{array}$ & $\begin{array}{c}0.35 \\
{[0.01,0.88]}\end{array}$ \\
\hline$\beta_{S_{1}=0}$ & $\mathcal{N}(0.25,0.15)$ & $\begin{array}{c}0.50 \\
{[0.05,0.95]}\end{array}$ & $\begin{array}{c}0.57 \\
{[0.09,0.96]}\end{array}$ \\
\hline$\beta_{S_{1}=1}$ & $\mathcal{N}(0.25,0.15)$ & $\begin{array}{c}0.84 \\
{[0.46,0.99]}\end{array}$ & $\begin{array}{c}0.86 \\
{[0.56,0.99]}\end{array}$ \\
\hline$\rho_{S_{1}=0}$ & $\mathcal{N}(0.8,1.0)$ & $\begin{array}{c}0.96 \\
{[0.92,0.99]}\end{array}$ & $\begin{array}{c}0.94 \\
{[0.90,0.97]}\end{array}$ \\
\hline$\rho_{S_{1}=1}$ & $\mathcal{N}(0.8,1.0)$ & $\begin{array}{c}0.85 \\
{[0.77,0.91]}\end{array}$ & $\begin{array}{c}0.74 \\
{[0.52,0.88]}\end{array}$ \\
\hline$\sigma_{\epsilon S_{2}=0}^{2}$ & $\mathrm{IG}(2.5,0.75)$ & $\begin{array}{c}1.76 \\
{[1.23,2.554]}\end{array}$ & $\begin{array}{c}1.80 \\
{[1.22,2.68]}\end{array}$ \\
\hline$\sigma_{\epsilon S_{2}=1}^{2}$ & $\mathrm{IG}(2.5,0.75)$ & $\begin{array}{c}0.11 \\
{[0.08,0.16]}\end{array}$ & $\begin{array}{c}0.11 \\
{[0.07,0.16]}\end{array}$ \\
\hline$\pi^{\mathrm{LR}}$ & $\mathcal{N}(2.0,0.075)$ & $\begin{array}{c}2.09 \\
{[1.78,2.36]}\end{array}$ & $\begin{array}{c}2.03 \\
{[1.74,2.33]}\end{array}$ \\
\hline$\rho_{\pi}$ & $\mathcal{N}(0.9,0.1)$ & - & $\begin{array}{c}0.97 \\
{[0.92,0.99]}\end{array}$ \\
\hline$\sigma_{\xi S_{2}=0}^{2}$ & $\operatorname{IG}(2.5,0.75)$ & - & $\begin{array}{c}0.63 \\
{[0.20,1.60]}\end{array}$ \\
\hline$\sigma_{\xi S_{2}=1}^{2}$ & $\mathrm{IG}(2.5,0.75)$ & - & $\begin{array}{c}0.18 \\
{[0.09,0.32]}\end{array}$ \\
\hline$\phi_{S_{1}=0}$ & $\mathcal{N}(0.4,0.01)$ & $\begin{array}{c}0.42 \\
{[0.25,0.61]}\end{array}$ & $\begin{array}{c}0.25 \\
{[0.07,0.45]}\end{array}$ \\
\hline$\phi_{S_{1}=1}$ & $\mathcal{N}(0.6,0.01)$ & $\begin{array}{c}0.87 \\
{[0.79,0.95]}\end{array}$ & $\begin{array}{c}0.55 \\
{[0.33,0.78]}\end{array}$ \\
\hline$\sigma_{\eta S_{2}=0}^{2}$ & $\mathrm{IG}(2.5,0.75)$ & $\begin{array}{l}2.76 \\
{[1.96,3.91]}\end{array}$ & $\begin{array}{c}1.66 \\
{[0.71,2.71]}\end{array}$ \\
\hline$\sigma_{\eta S_{2}=1}^{2}$ & $\mathrm{IG}(2.5,0.75)$ & $\begin{array}{c}0.68 \\
{[0.49,0.95]}\end{array}$ & $\begin{array}{c}0.45 \\
{[0.27,0.74]}\end{array}$ \\
\hline$p_{01, S_{1}}$ & $\operatorname{Beta}(5,95)$ & $\begin{array}{c}0.05 \\
{[0.02,0.09]}\end{array}$ & $\begin{array}{c}0.05 \\
{[0.02,0.09]}\end{array}$ \\
\hline$p_{10, S_{1}}$ & $\operatorname{Beta}(5,95)$ & $\begin{array}{c}0.05 \\
{[0.02,0.08]}\end{array}$ & $\begin{array}{c}0.06 \\
{[0.02,0.10]}\end{array}$ \\
\hline$p_{01, S_{2}}$ & $\operatorname{Beta}(5,95)$ & $\begin{array}{c}0.06 \\
{[0.03,0.10]}\end{array}$ & $\begin{array}{c}0.06 \\
{[0.03,0.10]}\end{array}$ \\
\hline$p_{10, S_{2}}$ & $\operatorname{Beta}(5,95)$ & $\begin{array}{c}0.05 \\
{[0.02,0.08]}\end{array}$ & $\begin{array}{c}0.04 \\
{[0.02,0.07]}\end{array}$ \\
\hline $\log (\mathrm{ML})$ & - & -570.39 & -561.92 \\
\hline
\end{tabular}

Notes: Figures reported in the table are posterior means; [5th, 95th] percentiles of the simulated posteriors in squared brackets. Moments of the priors generally report the mean and variance of the density in brackets, with the exception of the Beta priors for the switching probabilities, which are defined by their shape parameters. Log marginal data density are computed using the output of the MCMC simulators. The model favored by the data attains the highest marginal data density. Description of the different models: See Figure 1. Details on estimation procedure reported in the text.

\section{EMPIRICAL EVIDENCE}

\subsection{Trend Inflation}

Figure 1 displays the U.S. inflation rate along with our two different estimated inflation targets in the post-WWII period. The estimate (posterior mean) of the 


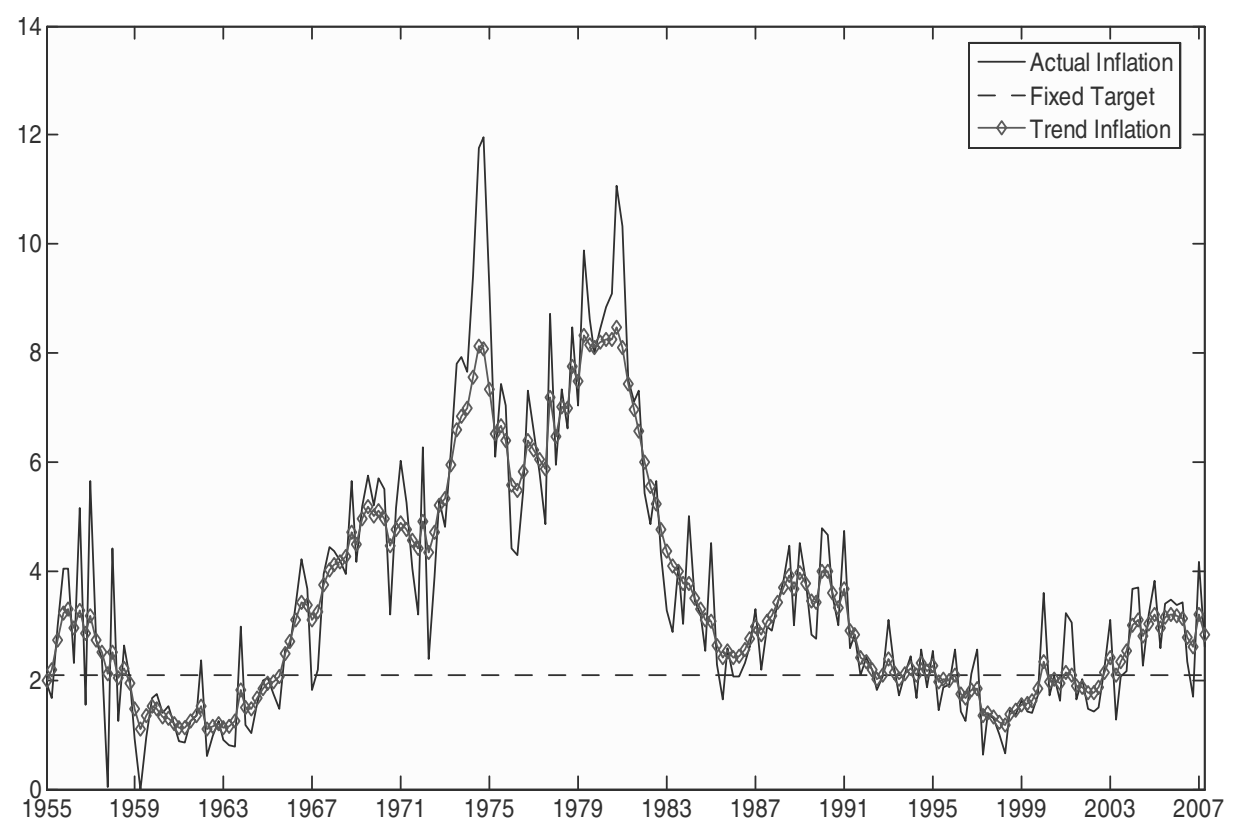

FIGURE 1. Raw inflation rate and estimated trend inflation. Fixed target: restricted model with constant inflation target. Trend inflation: unrestricted model with time varying inflation target as described in the text.

fixed inflation target is $2.09 \%$. A very different picture emerges when the target is allowed to vary over time. The minimum value is estimated to be 1.12 in 1962:II, a phase during which inflation was well under control. Not surprisingly, the highest estimate for trend inflation falls in 1980:IV, at the end of the inflation drift that occurred in the 1970s and just before the dramatic disinflation of the early 1980s. In first approximation, trend inflation oscillates around a relatively moderate value from the mid-1950s up to the mid-1960s; then it drifts up in correlation with raw inflation, somewhat stabilizes around a new mean value in the second part of the 1970s, dramatically falls at the beginning of the 1980s, and finally stabilizes during the great moderation. Our estimated inflation target is very close to the one proposed by Ireland (2007) and Stock and Watson (2007), belongs to the $90 \%$ credible set put forth by Cogley and Sbordone (2008), and is in line-at least, in a first approximation - with the latent factor identified by Cogley et al. (2010).

Interesting findings concerning the time-varying inflation target process also arise. Table 1 reports the corresponding estimates. Trend inflation's estimated persistence is high - the posterior mean of $\rho_{\pi}$ is equal to 0.97 , i.e., the inflation target process is close to a random walk. ${ }^{8}$ This result supports the modeling choice adopted by Kozicki and Tinsley (2005), Ireland (2007), Stock and Watson (2007), Cogley and Sbordone (2008), and Cogley et al. (2010). The state-dependent persistence of the inflation gap is found to be dramatically lower ( 0.25 vs. 0.55$)$ 
under the active policy regime. This evidence is consistent with that put forward by Cogley et al. (2010), who interpret it as a causal relationship in the context of a new Keynesian AD/AS monetary model.

Importantly, the superiority of the trend inflation model is given formal statistical support, in that the marginal-likelihood-based comparison suggests a difference larger than $8 \log$ points (see Table 1, last row). ${ }^{9}$

\subsection{Estimated Coefficients}

Table 1 reports the posterior mean estimates-along with the 5th and 95th percentiles - of our policy rules. Several considerations are in order.

In the presence of a fixed inflation target, the estimated Taylor rule parameters under the active and passive regimes line up with those already present in the literature. ${ }^{10}$ Interestingly, different findings emerge when trend inflation is allowed to be part of the model. In particular, we observe a dramatic fall in the Taylor parameter $\alpha$ under passive monetary policy. The reaction to inflation is basically halved with respect to that estimated with the FT model, from 0.79 to 0.35 , a value much lower than those proposed in the literature. Consequently, the presence of trend inflation appears to augment the gap between the reactions to inflation in the active vs. passive regimes. Possibly, this suggests that the macroeconomic influence of U.S. monetary policy exerted when switching from a passive to an active monetary policy may have been underestimated so far. A more complete assessment of this switch would require the use of simulations with a full-fledged structural model, an endeavor that we postpone to future research. Notably, Cogley et al. (2010) find a much higher value of $\alpha$ when focusing on the 1970s. The difference between their results and ours is likely to be due to their choice to perform full-system estimation conditional on equilibrium uniqueness, a choice that forces the parameter $\alpha$ to assume values satisfying the Taylor principle (greater than one).

Moving to the remaining parameters, the policy reaction to the output gap is smaller under the active policy regime. This result, which arises both under FT and under TI, confirms the intuition of Clarida et al. (2000), who find an increase in the relative weight assigned by policymakers to inflation stabilization with respect to output stabilization. Interest rate smoothing is found to be a relevant empirical ingredient to track U.S. policy decisions, in line with Castelnuovo (2003). As already noticed by Clarida et al. (2000), the degree of gradualism is higher when the policy is active. This evidence may be rationalized in light of the influence that gradual policy moves may exert on households' expectations [Woodford (2003b)].

Finally, heteroskedasticity of shocks is also clearly preferred by the data. In particular, both standard monetary policy and trend inflation shocks turn out to be heteroskedastic. Again, this latter finding corroborates recent empirical evidence put forward by Cogley et al. (2010), Bianchi (in press), and Liu et al. (2011), among others. 


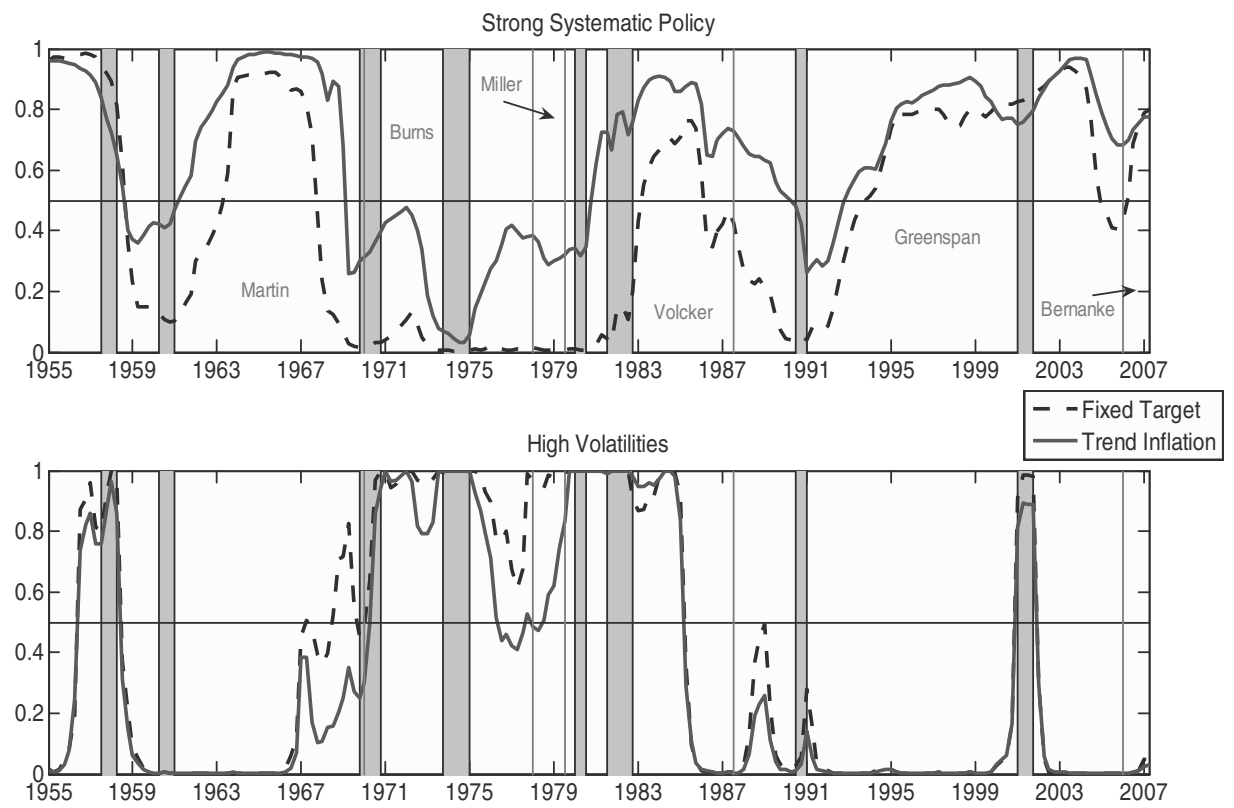

FIGURE 2. Fixed inflation target vs. trend inflation: estimated probabilities. Description of the models provided in the text. Smoothed estimates of the probability of being in the "active" monetary policy regime (upper panel) and in the "high" volatility regime (lower panel). Gray vertical bars identify NBER recessions, black vertical bars identify Fed's chairmanships.

\subsection{Estimated Regime Switches}

Figure 2, top panel, plots the evolution of the probability of being in an active monetary policy regime conditional on our estimated models. Although the 1970s are clearly associated with a passive monetary policy regime, the 1960s are associated with active policy conduct. The 1980s and 1990s are also characterized by switches in the policy stance. In particular, the 1991 recession is clearly pinpointed as a phase in which the Fed acted passively.

Notice that both models predicts recurrent regime switches. Interestingly, Figure 2 , top panel, reveals relevant differences in the dating suggested by the FT vs. TI models. In particular, the FT framework suggests a switch toward active monetary policy in 1983:I, much later than the appointment of Paul Volcker as Chairman of the Federal Reserve, which occurred in August 1979. In contrast, the TI model suggests a shift to active policy in 1980:IV, shortly after Volcker's appointment. Going back in time, on February 1970, Arthur Burns was appointed by Richard Nixon as chairman of the Fed. As stressed by Bianchi (in press), Burns is typically regarded as responsible for the great inflation drift of the 1970s, possibly because of political pressures coming from the White House. Our trend inflation model dates the switch from active to passive monetary policy in 1969:II, very close to Burns's appointment. In contrast, the fixed target model anticipates such an 
event, with a dating suggesting 1968:I. As regards the 1991 recession, the trend inflation model identifies such an event more precisely, suggesting a passive policy in correspondence to the subsample 1989:III-1993:III, much shorter than the 1987:IV-1994:I implied by the fixed target model. In general, the model with a constant inflation target appears to underestimate the length of the periods in which the Fed has actively fought inflation fluctuations.

Admittedly, this underestimation is far from being substantial. Moreover, the FT model also captures the relevant events that occurred in the sample under scrutiny, first and foremost the switch toward an activist policy that occurred with the advent of Paul Volcker at the end of the 1970s. Hence, the FT model offers, in first approximation, a good description of post-WWII U.S. monetary policy. However, the precision of the dating associated with the TI setup appears to be superior to that associated with FT.

The episodes of passive policy identified by our empirical investigation may be intriguingly related to our estimates of the effective inflation target. We isolate (roughly) three episodes of passive policy, the late 1950s-early 1960s, the 1970s, and the early 1990s. During the first two of these episodes, the effective inflation target increased. During the third episode, our estimate of trend inflation decreased. In all these periods, the results might be taken to suggest that the Federal Reserve was acting as if it were willing not only to see a transitory deviation of inflation, but also to accommodate a more persistent shift in inflation (i.e., a shift in the inflation target). It must be noted that although the "passive" label is most often used to refer to periods of ineffective policy during which inflation increased to subsequently undesirable levels, this interpretation is usually applied to periods when policy was not sufficiently tight to bring inflation back down to its target. In fact, the third passive-policy episode appears to be one of opportunistic disinflation, during which the central bank aimed at locking in lower inflation [see Orphanides and Wilcox (2002) for the theoretical foundations of such approach, and Orphanides et al. (2006) for a quantitative assessment of its relevance].

\subsection{Marginal-Likelihood Computation}

Estimation of the Marginal Likelihood. In Bayesian statistics it is common practice to use the marginal likelihood to measure the goodness-of-fit. This quantity is defined as

$$
\begin{aligned}
& m(\boldsymbol{I}, \boldsymbol{X} \mid \mathcal{M}) \\
& \quad=\int p\left(\boldsymbol{I}, \boldsymbol{X} \mid \boldsymbol{\pi}^{*}, \boldsymbol{S}_{1}, \boldsymbol{S}_{2}, \boldsymbol{\theta}, \mathcal{M}\right) p\left(\boldsymbol{\pi}^{*}, \boldsymbol{S}_{1}, \boldsymbol{S}_{2} \mid \boldsymbol{\theta}, \mathcal{M}\right) p(\boldsymbol{\theta} \mid \mathcal{M}) d \boldsymbol{\theta} d \boldsymbol{\pi}^{*} d \boldsymbol{S}_{1} d \boldsymbol{S}_{2},
\end{aligned}
$$

where $\boldsymbol{I}=\left\{i_{t}, t=1, \ldots, T\right\}$ is the nominal interest rate, $\boldsymbol{X}=(\boldsymbol{\pi}, \boldsymbol{y})$, in which $\boldsymbol{\pi}=\left\{\pi_{t}, t=1, \ldots, T\right\}$ is the inflation rate and $\boldsymbol{y}=\left\{y_{t}, t=1, \ldots, T\right\}$ is the output gap, $\pi^{*}=\left\{\pi_{t}^{*}, t=1, \ldots, T\right\}$ stands for the unobservable inflation target, $\boldsymbol{\theta}$ collects the parameters of interest, $\mathcal{M}$ indicates a given model, and $p(\boldsymbol{\theta} \mid \mathcal{M})$ is 
the set of prior distributions. In the following steps we suppress the model index $\mathcal{M}$ for conciseness.

Many techniques have been proposed in the literature to evaluate the marginal likelihood. A review of some Monte Carlo alternatives is given in Han and Carlin (2001). We compute the marginal likelihood through the modified harmonic mean (MHM) of Gelfand and Dey (1994) based on the result

$$
p(\boldsymbol{I}, \boldsymbol{X})^{-1}=\int \frac{h(\boldsymbol{\theta})}{p(\boldsymbol{I}, \boldsymbol{X} \mid \boldsymbol{\theta}) p(\boldsymbol{\theta})} p(\boldsymbol{\theta} \mid \boldsymbol{I}, \boldsymbol{X}) d \boldsymbol{\theta},
$$

in which $h(\boldsymbol{\theta})$ is a weighting function. A Monte Carlo estimate of (6) is

$$
\hat{p}(\boldsymbol{I}, \boldsymbol{X})^{-1}=\frac{1}{N} \sum_{i=1}^{N} \frac{h\left(\boldsymbol{\theta}^{(i)}\right)}{p\left(\boldsymbol{I}, \boldsymbol{X} \mid \boldsymbol{\theta}^{(i)}\right) p\left(\boldsymbol{\theta}^{(i)}\right)},
$$

in which $\boldsymbol{\theta}^{(i)}$ are draws from the posterior distribution.

The computation of the weighting function $h(\boldsymbol{\theta})$ plays a key role in this context. Geweke (1999) proposes a weighting function based on a truncated multivariate normal random variable centered at the posterior mean and with dispersion the variance-covariance matrix. Here we consider the generalization of Sims et al. (2008). In this framework, $h(\boldsymbol{\theta})$ is a truncated elliptical distribution centered at the posterior mode of $\boldsymbol{\theta}$, namely $\hat{\boldsymbol{\theta}}$, and with dispersion matrix $\hat{\Omega}=\frac{1}{N} \sum_{i=1}^{N}\left(\boldsymbol{\theta}^{(i)}-\hat{\boldsymbol{\theta}}\right)\left(\boldsymbol{\theta}^{(i)}-\hat{\boldsymbol{\theta}}\right)^{\prime}$. As pointed out in Sims et al. (2008), this choice results in a considerable improvement in switching regime models. A crucial point for the estimation of the marginal likelihood is the evaluation of $p\left(\boldsymbol{I}, \boldsymbol{X} \mid \boldsymbol{\theta}^{(i)}\right)$. We recur to the approximate solution proposed in Kim and Nelson (1999, 97-106) in which the Kalman and Hamilton filters are merged together, and in which the mixture component is collapsed at the end of each iteration to keep the algorithm feasible. To apply this method, it is convenient to rewrite the model through the state space representation

$$
\begin{gathered}
\boldsymbol{y}_{t}=\Gamma_{t}^{-1} \mu_{y, t}+\Gamma_{t}^{-1} H_{t} \Pi_{t}^{*}+\Gamma_{t}^{-1} \tilde{\epsilon}_{t}, \\
\Pi_{t}^{*}=\left[\begin{array}{c}
\pi_{t}^{*} \\
\pi_{t-1}^{*}
\end{array}\right]=\left[\begin{array}{c}
\left(1-\rho_{\pi}\right) \pi^{\mathrm{LR}} \\
0
\end{array}\right]+\left[\begin{array}{cc}
\rho_{\pi} & 0 \\
1 & 0
\end{array}\right]\left[\begin{array}{c}
\pi_{t-1}^{*} \\
\pi_{t-2}^{*}
\end{array}\right]+\left[\begin{array}{cc}
1 & 0 \\
0 & 0
\end{array}\right]\left[\begin{array}{c}
\xi_{S_{2}, t} \\
0
\end{array}\right],
\end{gathered}
$$

in which

$$
\begin{gathered}
\boldsymbol{y}_{t}=\left[\begin{array}{l}
i_{t} \\
\pi_{t}
\end{array}\right], \mu_{y, t}=\left[\begin{array}{c}
\left(1-\rho_{S_{1}, t}\right)\left[\bar{r}+\beta_{S_{1}, t}\right]+\rho_{S_{1}, t} i_{t-1} \\
\phi_{S_{1}, t} \pi_{t-1}
\end{array}\right], \\
\Gamma_{t}=\left[\begin{array}{cc}
1 & -\left(1-\rho_{S_{1}, t}\right)\left(1+\alpha_{S_{1}, t}\right) \\
0 & 1
\end{array}\right], H_{t}=\left[\begin{array}{cc}
-\left(1-\rho_{S_{1}, t}\right) \alpha_{S_{1}, t} & 0 \\
1 & \phi_{S_{1}, t}
\end{array}\right],
\end{gathered}
$$

and

$$
\tilde{\epsilon}_{t}=\left[\begin{array}{c}
\epsilon_{S_{2}, t} \\
\eta_{S_{2}, t}
\end{array}\right]
$$


Furthermore, it is also useful to define a new switching regime process $S$ as follows:

$$
S_{t}=\left\{\begin{array}{llll}
0 & \text { if } S_{1, t}=0 & \text { and } & S_{2, t}=0 \\
1 & \text { if } S_{1, t}=0 & \text { and } & S_{2, t}=1 \\
2 & \text { if } S_{1, t}=1 & \text { and } & S_{2, t}=0 \\
3 & \text { if } S_{1, t}=1 & \text { and } & S_{2, t}=1,
\end{array}\right.
$$

with transition probabilities $P=P_{1} \otimes P_{2}$.

Model Comparison. We find statistical evidence in favor of the two-chain setup as opposed to the single-chain framework. When conditioning to a single chain $S_{1}=S_{2}=S$, we obtain marginal likelihoods -563.45 for the trend inflation model, and -584.28 for the fixed target framework. These likelihoods clearly suggest a worse fit than that of our best model, -561.92. Again, our model embedding trend inflation turns out to be statistically superior. More importantly, the comparison involving the two models with trend inflation substantially favors the more flexible two-chain framework, with a difference in terms of marginal likelihood of about $14 \log$ points. This result corroborates Bianchi's (in press) and Davig and Doh's (2009) findings on the relevance of modeling different chains for policy parameters and shocks. Clearly, this is evidence that cannot be captured by the quite popular "pre- vs. post-Volcker" view of U.S. policy conduct.

\section{TREND INFLATION: A LITERATURE TOUR}

How does our estimated inflation target compare with the evidence already present in the literature? Figure 3 contrasts our trend inflation estimate with a number of differently computed, recently proposed measures: Kozicki and Tinsley (2005, 2009), Ireland (2007), Arouba and Schorfheide (2011), and Coibion and Gorodnichenko (2011). ${ }^{11}$ For the sake of readibility, panel $[1,1]$ replicates our Figure 1 and shows the pattern of quarterly GDP inflation along with our trend inflation estimate. Panel [1,2] contrasts our estimated target with Kozicki and Tinsley's (2005) estimate. Kozicki and Tinsley (2005) employ a VAR model featuring variations in the Fed's inflation target that are imperfectly perceived by the private sector. Such changes partly reflect the Fed's response to supply shocks hitting the U.S. economy over the post-WWII period. Kozicki and Tinsley's (2005) estimated target moves from values smaller than $2 \%$ in the early 1960 s to values close to $8 \%$ at the end of the 1970s. Their trend inflation measure takes values somewhat higher than ours in the late 1960s and early 1970s. Interestingly, their estimated inflation target drops to zero during the Volcker disinflation; then it gradually returns to around 4\% from the mid-1980s to the mid-1990s, and slightly decreases later on. The somewhat richer dynamics of Kozicki and Tinsley's (2005) estimate may be due to their learning mechanism modeling the Federal Reserve's imperfect credibility, which makes the private sector unable to distinguish perfectly between permanent target shocks and transitory policy shocks. However, the overall sample volatility, as measured by the standard deviation of the estimated process, is actually very 

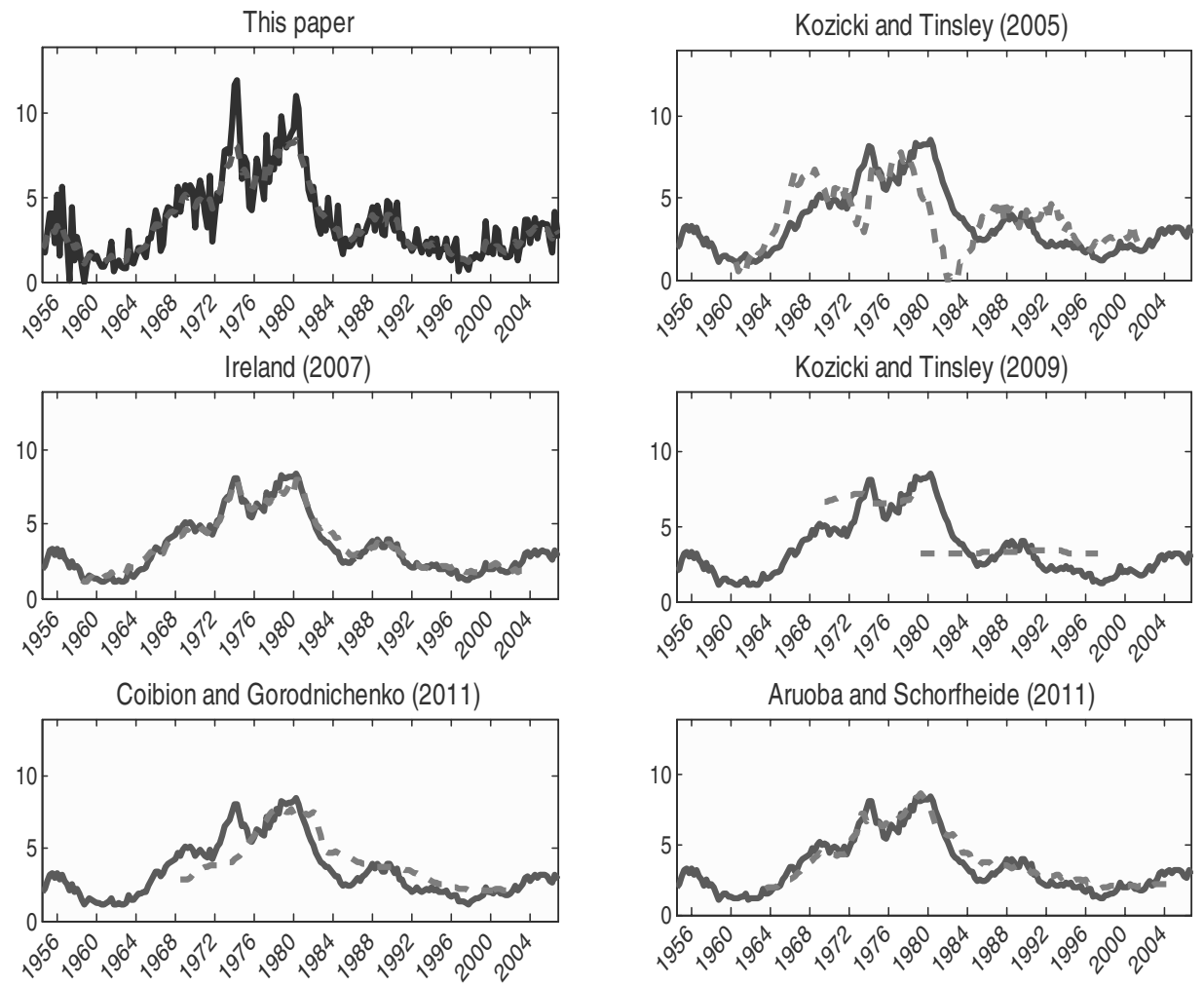

FIGURE 3. Trend inflation estimates: A comparison. Panel [1,1]: Solid line: actual inflation; dashed line: our trend inflation estimates. Other panels: Solid lines: our trend inflation estimate; dashed lines: other contributions' trend inflation estimates. Sources of other contributions' estimates reported in the text.

similar: it reads 1.91 as for Kozicki and Tinsley's (2005) vs. 1.96 as for our estimate.

Ireland (2007) estimates a microfounded DSGE model of the business cycle with perfect information enjoyed by all agents of the economic system. The trend inflation process is modeled as a random walk. ${ }^{12}$ His estimate of the inflation target is quite similar to the one proposed by Stock and Watson (2007), and it is statistically consistent with the one proposed by Cogley and Sbordone (2008), once the uncertainty surrounding the latter is taken into account. Panel $[2,1]$ superimposes Ireland's (2007) estimate of the Federal Reserve's target on ours. The similarity between the two measures is impressive, with a correlation amounting to 0.98 for the largest sample they share. This is an interesting result, because our model imposes a set of restrictions smaller than Ireland's (2007), but it is still able to produce an estimate comparable to the one emerging out of a macroeconomic model derived from first principles.

A remarkably different picture emerges from the comparison between our estimate and Kozicki and Tinsley's (2009). They estimate a policy rule with 
time-varying coefficients using real-time Greenbook data and imposing a set of restrictions consistent with intermediate money supply targeting. The resulting trend inflation is estimated to lie between 6.1 and $7.2 \%$ in the period 1970-1980, and then dramatically falls to about $3 \%$ in the 1980s and 1990s, a phase in which no intermediate money supply targeting is implemented. ${ }^{13}$ Panel $[2,2]$ shows a dramatic difference between our target and theirs. These difference may be due, among other reasons, to the fact that we do not consider the restrictions implied by money supply targeting.

Coibion and Gorodnichenko (2011) propose an estimate of trend inflation conditional on a Taylor rule featuring time-varying coefficients and estimated with real-time Greenbook data. This rule features a time-varying intercept, which they interpret as being a combination of time-dependent objects such as trend inflation, the equilibrium real interest rate, and the target growth rates for the output growth and the output gap. Assumptions on the evolution of the last three objects enable Coibion and Gorodnichenko (2011) to recover the evolution of the trend inflation process. Their estimated target, displayed in Panel [3,1], turns out to be much smoother than ours, with an empirical standard deviation of 1.76 vs. the larger 2.13 associated with our estimate (conditional on Coibion and Gorodnichenko's sample). However, a similar pattern emerges, in that both measures clearly follow the upward inflation trend of the 1970s, the Volcker disinflation occurred in the early 1980s, and a somewhat gradual stabilization of inflation was realized in the 1990s. Notably, the correlation between these two measures of trend inflation is 0.80 .

Finally, a different approach to computing trend inflation is followed by Aruoba and Schorfheide (2011). They combine three different measures of inflationquarterly GDP inflation filtered through a one-sided bandpass filter and oneyear- and ten-year-ahead inflation expectations from the Survey of Professional Forecasters - by using a small state-space model. Then they extract the common factor via the Kalman filter. Panel [3,2] plots Arouba and Schorfheide's (2011) estimate. As in the case of Ireland's (2007) estimate, the similarity is striking, with a correlation between our estimate and Aruoba and Schorfheide's equal to 0.95. This is interesting, in light of the fact that Aruoba and Schorfheide's estimate involves measures of expectations that are not considered in our analysis.

Figure 3 displays the heterogeneity of estimates present in the literature. In summary, our estimate of trend inflation is extremely close to those of Ireland (2007) and Aruoba and Schorfheide (2011); fairly similar to the ones proposed by Coibion and Gorodnichenko (2011) and, to some extent, Kozicki and Tinsley (2005); and quite different from Kozicki and Tinsley's (2009).

A note of caution is warranted here. One must be careful in contrasting these estimates of trend inflation and in relating them to the effective inflation target of monetary policy. Some estimates may more appropriately map into estimates of the private sector's perception of the effective inflation target of monetary policy. For instance, estimates extracted from measures of expected inflation [as in Aruoba and Schorfheide (2011)] more likely correspond with the private sector's perception 
of the effective target of monetary policy. In some studies, the two concepts are assumed to be the same [e.g., Ireland (2007)]. In other studies, the concepts are explicitly identified separately [e.g., Kozicki and Tinsley (2005)]. In this paper, it is more appropriate to think of the estimated concept as the effective target of monetary policy. Also, in drawing these comparisons, one should keep in mind that differences may be due to a variety of sources, including differences in the investigated samples, data transformation [e.g., the quarterly inflation rate used in our exercise and in Ireland (2007), as opposed to the four-quarter inflation rate employed by Kozicki and Tinsley (2005)], structure imposed on the data [e.g., simple rules as in our case, Kozicki and Tinsley (2005), and Coibion and Gorodnichenko (2011), structural vector autoregressions as in Kozicki and Tinsley (2005), state-space representations as in Aruoba and Schorfheide (2011), and DSGE frameworks as in Ireland (2007)], and vintage of the data ("real-time" vs. "revised" data). The relevance of this last element is analyzed in the following section. ${ }^{14}$

\section{AN INVESTIGATION WITH GREENBOOK DATA}

The empirical objects the Federal Reserve is assumed to react to in our baseline analysis are constructed by employing revised data, as it is common in the empirical macro literature concerned with the behavior of U.S. policymakers-see, among others, Clarida et al. (2000), Lubik and Schorfheide (2004), Ireland (2007), Cogley and Sbordone (2008), Cogley et al. (2010), Aruoba and Schorfheide (2011), Bianchi (in press), and Liu et al. (2011). This choice is also motivated by our willingness to contrast our results with those already present in the literature, above all for trend inflation estimates. However, although simple rules are often estimated with revised data, real-time data actually available to policymakers when they set their policy are probably more suited to interpreting and characterizing policy rules. Some instances of estimation conducted with real-time data are Orphanides (2001), Kozicki and Tinsley (2009), and Coibion and Gorodnichenko (2011). We then engage in estimation with Greenbook data released by the Federal Reserve Bank of Philadelphia. We consider the two-quarter-ahead inflation expectations (quarterly growth rates) of the GNP/GDP price level, as well as the nowcast of the output gap measure. ${ }^{15}$ The choice of this timing is driven by some recent findings by Coibion and Gorodnichenko (2011), who show that such a formulation is preferred by the data (according to standard information criteria) with respect to a variety of alternatives. Given the delay with which Greenbook forecasts are released, our sample covers 1969:I-2005:VI.

Figure 4 juxtaposes our baseline and Greenbook data estimates. Although we can identify some differences between our two estimated processes, all in all a striking similarity emerges - their degree of correlation is 0.93 . Turning to the estimated parameters of our empirical model, Table 2 reveals a few differences with respect to the baseline scenario. In particular, the estimated reaction to inflation is stronger in both regimes; that of output is milder in both regimes; the variance 

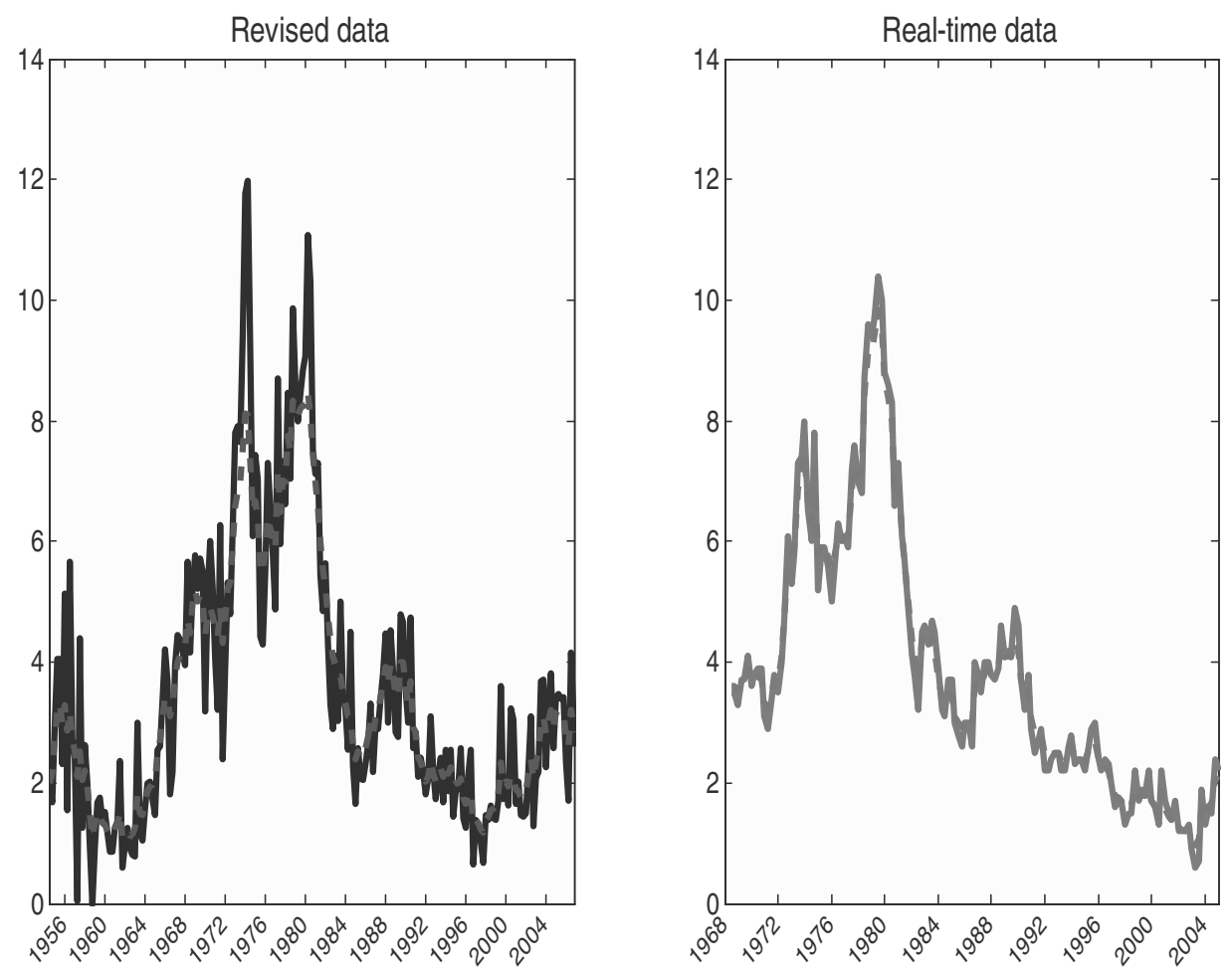

FIGURE 4. Estimated trend inflation: Real time vs. revised data. Left panel: Estimates obtained with revised data, quarterly GDP deflator inflation. Solid line: actual inflation, dashed line: trend inflation estimate. Right panel: Estimates obtained with Greenbook inflation and output data (as documented in the text). Solid line: Greenbook expected inflation (two quarters ahead), dashed line: trend inflation estimate.

of the monetary policy shock is higher in the active regime. However, and most importantly for our analysis, the marginal likelihood of our model with trend inflation, which reads -308.24 , is substantially greater than that associated with the model featuring a fixed target, which amounts to -325.56 . Therefore, our main result - a policy rule featuring a time-varying inflation target on top of switching policy parameters and shocks' heteroskedasticity—is robust to the employment of Greenbook data.

Interpreting Our Result. In light of this result, some further considerations are in order. Our trend inflation estimate is robust to the employment of real-time data. However, Figure 4 seems to suggest that the Federal Reserve has mainly responded to very transitory deviations of inflation from the target. This result is not new in the literature. Eyeball econometrics suggest that both Ireland (2007; see our Figure 4, panel [2,1]) and Aruoba and Schorfheide (2011; see our Figure 4, panel $[3,2])$ achieve very similar conclusions. In light of the methodologies employed by Ireland (2007) and Aruoba and Schorfheide (2011), which are different from ours, our set of priors is unlikely to drive this result. ${ }^{16}$ A comparison with Kozicki 
TABLE 2. Estimated monetary policy rules: Fixed target vs. trend inflation, Greenbook data

\begin{tabular}{|c|c|c|c|}
\hline Parameter & Prior & Fixed target & Trend inflation \\
\hline $\bar{r}$ & $\mathcal{N}(2.0,1.0)$ & $\begin{array}{l}2.05 \\
{[1.04,3.08]}\end{array}$ & $\begin{array}{l}2.87 \\
{[2.19,3.53]}\end{array}$ \\
\hline $1+\alpha_{S_{1}=0}$ & $\mathcal{N}(1.7,0.1) \mathbf{I}_{[1,5]}$ & $\begin{array}{c}2.02 \\
{[1.62,2.43]}\end{array}$ & $\begin{array}{c}1.82 \\
{[1.21,2.44]}\end{array}$ \\
\hline $1+\alpha_{S_{1}=1}$ & $\mathcal{N}(0.7,0.1) \mathbf{I}_{[0,1]}$ & $\begin{array}{c}0.66 \\
{[0.24,0.96]}\end{array}$ & $\begin{array}{c}0.61 \\
{[0.20,0.95]}\end{array}$ \\
\hline$\beta_{S_{1}=0}$ & $\mathcal{N}(0.25,0.15)$ & $\begin{array}{c}0.66 \\
{[0.41,0.90]}\end{array}$ & $\begin{array}{c}0.30 \\
{[0.03,0.92]}\end{array}$ \\
\hline$\beta_{S_{1}=1}$ & $\mathcal{N}(0.25,0.15)$ & $\begin{array}{c}0.69 \\
{[0.14,0.96]}\end{array}$ & $\begin{array}{c}0.71 \\
{[0.04,0.98]}\end{array}$ \\
\hline$\rho_{S_{1}=0}$ & $\mathcal{N}(0.8,1.0)$ & $\begin{array}{c}0.85 \\
{[0.79,0.90]}\end{array}$ & $\begin{array}{c}0.82 \\
{[0.61,0.95]}\end{array}$ \\
\hline$\rho_{S_{1}=1}$ & $\mathcal{N}(0.8,1.0)$ & $\begin{array}{c}0.82 \\
{[0.39,0.96]}\end{array}$ & $\begin{array}{c}0.82 \\
{[0.67,0.99]}\end{array}$ \\
\hline$\sigma_{\epsilon S_{2}=0}^{2}$ & $\mathrm{IG}(2.5,0.75)$ & $\begin{array}{c}2.25 \\
{[1.41,3.54]}\end{array}$ & $\begin{array}{c}2.54 \\
{[1.63,4.05]}\end{array}$ \\
\hline$\sigma_{\epsilon S_{2}=1}^{2}$ & $\mathrm{IG}(2.5,0.75)$ & $\begin{array}{c}0.15 \\
{[0.08,0.24]}\end{array}$ & $\begin{array}{c}0.13 \\
{[0.07,0.24]}\end{array}$ \\
\hline$\pi^{\mathrm{LR}}$ & $\mathcal{N}(2.0,0.075)$ & $\begin{array}{c}1.33 \\
{[1.74,1.88]}\end{array}$ & $\begin{array}{c}2.01 \\
{[1.71,2.30]}\end{array}$ \\
\hline$\rho_{\pi}$ & $\mathcal{N}(0.9,0.1)$ & - & $\begin{array}{c}0.98 \\
{[0.95,0.99]}\end{array}$ \\
\hline$\sigma_{\xi S_{2}=0}^{2}$ & $\mathrm{IG}(2.5,0.75)$ & - & $\begin{array}{c}0.50 \\
{[0.24,0.92]}\end{array}$ \\
\hline$\sigma_{\xi S_{2}=1}^{2}$ & $\mathrm{IG}(2.5,0.75)$ & - & $\begin{array}{c}0.10 \\
{[0.06,0.17]}\end{array}$ \\
\hline$\phi_{S_{1}=0}$ & $\mathcal{N}(0.4,0.01)$ & $\begin{array}{c}0.97 \\
{[0.93,0.99]}\end{array}$ & $\begin{array}{c}0.41 \\
{[0.21,0.61]}\end{array}$ \\
\hline$\phi_{S_{1}=1}$ & $\mathcal{N}(0.6,0.01)$ & $\begin{array}{c}0.71 \\
{[0.44,0.95]}\end{array}$ & $\begin{array}{c}0.60 \\
{[0.41,0.79]}\end{array}$ \\
\hline$\sigma_{\eta S_{2}=0}^{2}$ & $\mathrm{IG}(2.5,0.75)$ & $\begin{array}{c}0.77 \\
{[0.50,1.20]}\end{array}$ & $\begin{array}{c}0.25 \\
{[0.10,0.51]}\end{array}$ \\
\hline$\sigma_{\eta S_{2}=1}^{2}$ & $\mathrm{IG}(2.5,0.75)$ & $\begin{array}{c}0.20 \\
{[0.15,0.27]}\end{array}$ & $\begin{array}{c}0.11 \\
{[0.07,0.16]}\end{array}$ \\
\hline$p_{01, S_{1}}$ & $\operatorname{Beta}(5,95)$ & $\begin{array}{c}0.03 \\
{[0.01,0.07]}\end{array}$ & $\begin{array}{c}0.05 \\
{[0.02,0.09]}\end{array}$ \\
\hline$p_{10, S_{1}}$ & $\operatorname{Beta}(5,95)$ & $\begin{array}{c}0.06 \\
{[0.02,0.11]}\end{array}$ & $\begin{array}{c}0.05 \\
{[0.02,0.10]}\end{array}$ \\
\hline$p_{01, S_{2}}$ & $\operatorname{Beta}(5,95)$ & $\begin{array}{c}0.06 \\
{[0.02,0.10]}\end{array}$ & $\begin{array}{c}0.06 \\
{[0.03,0.11]}\end{array}$ \\
\hline$p_{10, S_{2}}$ & $\operatorname{Beta}[0.02,0.07] 0.04$ & $\begin{array}{c}0.04 \\
{[0.02,0.08]}\end{array}$ & \\
\hline $\log (\mathrm{ML})$ & - & -325.56 & -308.24 \\
\hline
\end{tabular}

Notes: Figures reported in the table are posterior means; [5th, 95th] percentiles of the simulated posteriors in squared brackets. Moments of the priors generally report the mean and variance of the density in brackets, with the exception of the Beta priors for the switching probabilities, which are defined by their shape parameters. Log marginal data density computed using the output of the MCMC simulators. The model favored by the data attains the highest marginal data density. Description of the different models: See Figure 1. Details on estimation procedure reported in the text.

and Tinsley's $(2005,2009)$ methodologies leads us to speculate that (i) the reduced number of restrictions on the relationships among the variables involved in our estimation and (ii) the limited information set we deal with (which omits, among other indicators, monetary aggregates) may be two of the reasons behind our result. Nevertheless, the difference in terms of marginal likelihoods is large enough (above all when Greenbook data are employed) to make us conclude that our 
models featuring a time-varying inflation target fits our data sets better than our constant-target framework.

Given the high degree of interest rate smoothing documented in our paper, as well as in previous contributions, our evidence [along with Ireland's (2007) and Aruoba and Schorfheide's (2011)] suggests that monetary policy may have responded to very volatile inflation deviations in a persistent manner. One possible interpretation reads as follows. Trend inflation represents a "short-run" inflation target, which is set by the Federal Reserve conditional on past and current inflation realizations. ${ }^{17}$ Observed inflation may very well enter policymakers' reaction function to determine at which new level trend inflation should be set to make the social costs of inflation stabilization over trend inflation acceptable. Of course, another possible interpretation is that this result, as puzzling as it is, must be due to some form of model misspecification. As already commented, we share this result with Ireland (2007) and Aruoba and Schorfheide (2011), who employ different models, observables, and estimation techniques to estimate trend inflation. Thus, if it is a puzzle, it concerns at least part of the literature. As with all puzzles, one would like to dig deeper and understand which omitted factors among the many candidates (among others, the role of money, learning, and policymakers' credibility) are those behind our result. We leave this interesting task to future research.

\section{CONCLUSIONS}

This paper estimates regime-switching Taylor rules with trend inflation for the post-WWII U.S. economy. Our empirical results support the rule embedding a time-varying inflation target as (a) statistically more powerful and (b) more able to pin down some relevant episodes of the post-WWII U.S. monetary policy history. Moreover, we find evidence in favor of regime shifts and monetary policy shocks' heteroskedasticity. Policy breaks are found not to be synchronized with variations in policy shocks' volatilities. Switches from a passive to an active policy (and vice versa) are found to be recurrent. In particular, we conclude that the appointment of Paul Volcker as chairman of the Federal Reserve was not necessarily the only relevant break that occurred in U.S. monetary policy in the post-WWII period, even controlling for changes in trend inflation. A comparison between our estimated target and a number of alternatives in the literature highlights the similarity between our trend inflation estimate and those proposed by Ireland (2007) and Aruoba and Schorfheide (2011). Our main result, which points to the empirical superiority of the model featuring trend inflation, turns out to be robust to the employment of real-time Greenbook data.

Our findings offer support for two lines of research. First, once it is established that the inflation target is a time-varying object, it is key to understand why it has evolved over time. Imperfect knowledge of the economic structure leading to a changing perception of the inflation-output trade-off by the Fed is one of the candidate explanations [Cogley and Sargent (2005), Primiceri (2006), Sargent 
et al. (2006), and Carboni and Ellison (2009)], but more research on this issue is needed. An insightful interpretation is offered by Kozicki and Tinsley (2009). They analyze extended Taylor rules to encompass a monetarist strategy of intermediate money growth targeting, which was the dominant strategy in the 1970s. They show that the effective inflation target in the 1970s exceeded ex ante inflation goals consistent with the FOMC money growth targets. This was due to sizeable shocks to money velocity and trend output. As a matter of fact, the authors conclude, the U.S. intermediate targeting of aggregate money growth rates in the 1970s was a distraction from objective performance measures of ultimate goals, such as longer-run inflation. The role played by monetary aggregates in shaping the U.S. macroeconomic dynamics, above all in the 1970s, represents a promising area for future research.

Second, normative considerations are in order. How should monetary policy be conducted in the presence of trend inflation? First attempts to tackle this issue are Ascari and Ropele (2007) and Ascari and Ropele (2009), but further research in this largely unexplored territory is clearly needed. We look forward to contributing to these exciting research agendas.

\section{NOTES}

1. We will use the terms "trend inflation" and "time-varying inflation target" as synonymous.

2. Following Leeper (1991), "active" ("passive") monetary policy refers to a policy that adjusts the nominal interest rate more (less) than one to one with movements in inflation.

3. Notably, Sims and Zha (2006) find that their best-fitting model displays no changes in the policy rule coefficients and heteroskedastic policy shocks. Nevertheless, they cannot reject models with an unstable policy rule on the basis of marginal likelihood comparisons.

4. Notably, Kozicki and Tinsley (2005) model the process of learning by private agents who do not observe the evolution of the true inflation target. Hence, they must learn whether variations in the observed policy rate are due to transitory policy shocks or to permanent shocks to the inflation target. Kozicki and Tinsley show that time-varying natural rates associated with movements in the perceived inflation target substantially influenced inflation and long-term interest rates in the United States. Another exercise jointly modeling trend inflation and learning is Milani (2009).

5. A comprehensive review on MCMC methods for regime-switching models may be found in Frühwirth-Schnatter (2006). Our computations were conducted with the software Ox (Version 5.1), which was developed by Jurgen A. Doornik [see Doornik (2001)]. Ox is freely available at http://www.doornik.com/products.html\#Ox . We confine the details of our estimation algorithm to a Technical Appendix available upon request.

6. It is straightforward to rewrite the Taylor rule (1) in the following (somewhat more conventional) version: $i_{t}=\left(1-\rho_{S_{1 t}}\right)\left(\gamma_{S_{1 t}}+\widetilde{\alpha}_{S_{1 t}} \pi_{t}+\beta_{S_{1 t}} y_{t}\right)+\rho_{S_{t}} i_{t-1}+\epsilon_{S_{2}, t}$, where $\gamma_{S_{1 t}} \equiv \bar{r}-\alpha_{S_{1 t}} \pi_{t}^{*}, \widetilde{\alpha}_{S_{1 t}} \equiv$ $1+\alpha_{S_{1 t}}$. Woodford (2003a) shows that the monetary policy reaction to inflation required to pin down a unique equilibrium in a new Keynesian framework, i.e., the Taylor principle, conditioned on a single state is $\widetilde{\alpha}_{S_{1 t}}>1-(1-\delta) \beta_{S_{t}} / \kappa$, where $\delta$ is firms' discount factor and $\kappa$ is the slope of the Phillips curve. Notably, if policymakers' reaction to business cycle fluctuations $\beta_{S_{t}}>0$, a value of $\widetilde{\alpha}_{S_{1 t}}$ lower than one (i.e., a value of $\alpha_{S_{1 t}}$ lower than zero) can still be consistent with a unique equilibrium. Therefore, the set of constraints we impose to identify the states might induce an overestimation of the "passive" monetary policy phases. We performed an ex post check based on our estimated $\alpha_{S_{1 t}}$ and $\beta_{S_{t}}$ and conditional on $\delta=0.99$ and $\kappa=0.1$ (a calibration widely adopted in the literature), and verified that such overestimation does not occur; i.e., the passive states we obtain remain unchanged when the exact Woodford (2003) uniqueness condition is considered. 
7. We retrieved the short-term policy rate (effective federal funds rate), the seasonally adjusted real GDP level $Y_{t}$, the estimate of the potential output made by the Congressional Budget Office $Y_{t}^{*}$, and the seasonally adjusted GDP deflator $P_{t}$ from the Federal Reserve Bank of St. Louis's website. Quarterly observations of the federal funds rate were obtained by averaging monthly observations. The output gap was computed as the percent $\log$ deviation of the real GDP from its potential level, i.e., $y_{t} \equiv 100 \log \left(Y_{t} / Y_{t}^{*}\right)$. The inflation rate was calculated as the quarter-by-quarter annualized growth rate of the GDP deflator, i.e., $\pi_{t} \equiv 400 \log \left(P_{t} / P_{t-1}\right)$. An investigation dealing with Greenbook forecasts is presented in Section 5.

8. As a consequence, the impact of the long-run target $\pi^{\mathrm{LR}}$ on the estimated trend inflation is de facto negligible.

9. Marginal likelihoods are computed via the method developed by Gelfand and Dey (1994). To account for the peculiarities of regime-switching models, the weighting function affecting the marginal likelihood is calculated with the algorithm developed by Sims et al. (2008). Details on the computation of the marginal likelihood are reported in an Appendix available upon request. The same ordering between models is obtained by implementing a computation of the marginal likelihood as suggested by Chib and Jeliazkov (2001).

10. See Clarida et al. (2000), Table II, p. 157; Lubik and Schorfheide (2004), Table 3 (first and third columns), p. 206.

11. The sources of these estimates are as follows. Kozicki and Tinsley $(2005,2009)$ and Ireland (2007): Original files provided by the authors. Coibion and Gordnichenko (2011): American Economic Review (website), their paper, zip file under "Additional Materials Download Data Set," "GreenBookForecasts for AER.xlsx" file, Trend Inflation, smoothed estimates. Monthly estimates converted to quarterly estimates by selecting the latest available observation within each quarter. Aruoba and Schorfheide (2011): American Economic Review (website), their paper, zip file under "Additional Materials—Download Data Set," "inflation-target.xls" file, "filtered f2" estimates.

12. Ireland (2007) contrasts different processes of trend inflation, some of which allow for a systematic reaction to structural shocks hitting the economic system. The role of such shocks, however, turns out to be empirically negligible. Panel $[2,1]$ shows the case labelled by Ireland (2007, Figure 5, page 1869) as "Federal Reserve's Target as Implied by the Constrained Model with an Exogenous Inflation Target."

13. Evidence in favor of a decline of the role of money growth in U.S. macroeconomic volatilities when moving from the 1970s to the great moderation is found by Castelnuovo (2012a).

14. The investigation of the relevance of sample selection and different methodologies represents valuable research that goes, however, beyond the scope of this paper.

15. As for the output gap, data concerning the 1969:I-2002:IV were taken from Coibion and Gorodnichenko (2011). Later observations were downloaded directly from the Federal Reserve Bank of Philadelphia's website. In the presence of more than one observation in a given quarter, we selected the latest observation available.

16. We experimented with two different perturbations of our priors, a smaller gap between the means of the parameter $\alpha$ (set to 1.3 in the active case and 0.8 in the passive scenario) and a smaller difference involving the means of the parameter $\phi_{S}$ (set to 0.45 in one scenario and 0.55 in the other one). The consequences of these perturbations for our trend inflation estimates turned out to be largely negligible.

17. Empirical support in favor of an "error-correction" mechanism linking trend inflation to past inflation for the post-WWII U.S. economy is provided by Castelnuovo (2012c).

\section{REFERENCES}

Aruoba, S. B. and F. Schorfheide (2011) Sticky prices versus monetary frictions: An estimation of policy trade-offs. American Economic Journal: Macroeconomics 3, 60-90.

Ascari, G. and T. Ropele (2007) Optimal monetary policy under low trend inflation. Journal of Monetary Economics 54, 2568-2583. 
Ascari, G. and T. Ropele (2009) Trend inflation, Taylor principle and indeterminacy. Journal of Money, Credit and Banking 41(8), 1557-1584.

Bianchi, F. (in press) Regime switches, agents' beliefs, and post-World War II U.S. macroeconomic dynamics. Review of Economic Studies.

Carboni, G. and M. Ellison (2009) The great inflation and the Greenbook. Journal of Monetary Economics 56(6), 831-841.

Castelnuovo, E. (2003) Taylor rules, omitted variables, and interest rate smoothing in the US. Economics Letters 81(1), 55-59.

Castelnuovo, E. (2007) Taylor rules and interest rate smoothing in the Euro area. Manchester School 75(1), 1-16.

Castelnuovo, E. (2010) Tracking U.S. inflation expectations with domestic and global determinants. Journal of International Money and Finance 29(7), 1340-1356.

Castelnuovo, E. (2012a) Estimating the evolution of money's role in the U.S. monetary business cycle. Journal of Money, Credit and Banking 44(1), 23-52.

Castelnuovo, E. (2012b) Policy switch and the Great Moderation: The role of equilibrium selection. Macroeconomic Dynamics 16(3), 449-471.

Castelnuovo, E. (2012c) Testing the structural interpretation of the price puzzle with a cost channel model. Oxford Bulletin of Economics and Statistics 74(3), 425-452.

Castelnuovo, E. and P. Surico (2010) Monetary policy shifts, inflation expectations and the price puzzle. Economic Journal 120(549), 1262-1283.

Chib, S. and I. Jeliazkov (2001) Marginal likelihood from the Metropolis-Hastings output. Journal of the American Statistical Association 96, 270-281.

Clarida, R., J. Gal, and M. Gertler (1998) Monetary policy rules in practice: Some international evidence. European Economic Review 42(6), 1033-1067.

Clarida, R., J. Gal, and M. Gertler (2000) Monetary policy rules and macroeconomic stability: Evidence and some theory. Quarterly Journal of Economics 115, 147-180.

Cogley, T., G. E. Primiceri, and T. Sargent (2010) Inflation-gap persistence in the U.S. American Economic Journal: Macroeconomics 2(1), 43-69.

Cogley, T. and T. Sargent (2005) The conquest of U.S. inflation: Learning and robustness to model uncertainty. Review of Economic Dynamics 8, 528-563.

Cogley, T. and A. Sbordone (2008) Trend inflation, indexation, and inflation persistence in the new Keynesian Phillips curve. American Economic Review 98(5), 2101-2126.

Coibion, O. and Y. Gorodnichenko (2011) Monetary policy, trend inflation and the Great Moderation: An alternative interpretation. American Economic Review 101, 341-370.

Davig, T. and T. Doh (2009) Monetary Policy Regime Shifts and Inflation Persistence. Working paper 08-16, Federal Reserve Bank of Kansas City.

Davig, Y. and E. Leeper (2006) Fluctuating macro policies and the fiscal theory. NBER Macroeconomics Annual, 247-298.

Doornik, J. A. (2001) Ox: An Object-Oriented Matrix Programming Language. London: Timberlake Consultants Press.

Favero, C. and T. Monacelli (2005) Fiscal Policy Rules and Regime (In)Stability: Evidence from the U.S. Mimeo, Bocconi University and IGIER.

Frühwirth-Schnatter, S. (2006) Finite Mixtures and Markov Switching Models. New York: Springer.

Gelfand, A. and D. Dey (1994) Bayesian model choice: Asymptotics and exact calculations. Journal of the Royal Statistical Society: Series B 56, 501-514.

Gerlach, S. and G. Schnabel (2000) The Taylor rule and interest rates in the EMU area. Economics Letters 67(2), 165-171.

Geweke, J. (1999) Using simulation methods for Bayesian econometric models: Inference, development and communication. Econometric Reviews 18, 1-73.

Golinelli, R. and R. Rovelli (2003) Monetary policy transmission, interest rate rules and inflation targeting in three transition economies. Journal of Banking and Finance 29, 183201. 
Hamilton, J. (1989) A new approach to the economic analysis of nonstationary time series and the business cycle. Econometrica 57, 357-384.

Hamilton, J., D. Waggoner, and T. Zha (2007) Normalization in econometrics. Econometric Reviews $26,221-252$.

Han, C. and B. Carlin (2001) MCMC methods for computing Bayes factors: A comparative review. Journal of the American Statistical Association 96, 1122-1132.

Ireland, P. (2007) Changes in Federal Reserve's inflation target: Causes and consequences. Journal of Money, Credit and Banking 39(8), 1851-1882.

Justiniano, A. and G. Primiceri (2008) The time-varying volatility of macroeconomic fluctuations. American Economic Review 98(3), 604-641.

Kim, C. and C. Nelson (1999) State-Space Models with Regime-Switching: Classical and Gibbs Sampling Approaches with Applications. Cambridge, MA: MIT Press.

Kozicki, S. and P. Tinsley (2005) Permanent and transitory policy shocks in an empirical macro model with asymmetric information. Journal of Economic Dynamics and Control 29, 1985-2015.

Kozicki, S. and P. Tinsley (2009) Perhaps the 1970s FOMC did what it said it did. Journal of Monetary Economics 56, 842-855.

Leeper, E. (1991) Equilibria under "active" and "passive" monetary and fiscal policies. Journal of Monetary Economics 27, 129-147.

Liu, Z., D. Waggoner, and T. Zha (2011) Sources of macroeconomic fluctuations: A regime-switching DSGE approach. Quantitative Economics 2(2), 251-301.

Lubik, T. and F. Schorfheide (2004) Testing for indeterminacy: An application to U.S. monetary policy. American Economic Review 94(1), 190-217.

Milani, F. (2009) Learning and the Evolution of the Fed's Inflation Target. Mimeo, University of California at Irvine.

Orphanides, A. (2001) Monetary policy rules based on real-time data. American Economic Review 91(4), 964-985.

Orphanides, A., D. Small, V. Wieland, and D. Wilcox (2006) A quantitative exploration of the opportunistic approach to disinflation. Journal of Monetary Economics 53(8), 1877-1893.

Orphanides, A. and D. Wilcox (2002) The opportunistic approach to disinflation. International Finance $5(1), 47-71$.

Primiceri, G. (2006) Why inflation rose and fell: Policymakers' beliefs and U.S. postwar stabilization policy. Quarterly Journal of Economics 121, 867-901.

Sargent, T., N. Williams, and T. Zha (2006) Shocks and government beliefs: The rise and fall of American inflation. American Economic Review 96(4), 1193-1224.

Schorfheide, F. (2005) Learning and monetary policy shifts. Review of Economic Dynamics 8(2), 392-419.

Sims, C. and T. Zha (2006) Were there regime switches in U.S. monetary policy? American Economic Review 96(1), 54-81.

Sims, C. A., D. F. Waggoner, and T. Zha (2008) Methods for inference in large multiple-equation Markov-switching models. Journal of Econometrics 146(2), 255-274.

Stock, J. H. and M. W. Watson (2007) Why has inflation become harder to forecast? Journal of Money, Credit and Banking 39(1), 3-33.

Taylor, J. (1993) Discretion versus policy rules in practice. Carnegie-Rochester Conference Series on Public Policy 39, 195-214.

Woodford, M. (2003a) Interest and Prices: Foundations of a Theory of Monetary Policy. Princeton, NJ: Princeton University Press.

Woodford, M. (2003b) Optimal interest-rate smoothing. Review of Economic Studies 70, 861-886. 